\title{
OS MODOS DE REPRESENTAÇÃO SOBRE A LÍNGUA INGLESA EM FÓRUNS ONLINE DE FUTUROS PROFESSORES DESTA LÍNGUA
}

\author{
ENGLISH STUDENT-TEACHERS' MODES OF \\ REPRESENTATION ABOUT ENGLISH IN ONLINE \\ DISCUSSION FORUNS
}

Júlio Araújo

Universidade Federal do Ceará

Andréia Turolo-Silva

Universidade Federal do Ceará

\section{Resumo}

Trata-se de uma pesquisa de caráter exploratório, de base etnográfica (FRAGOSO et.al, 2011), que teve como objetivos específicos identificar, descrever e explicar os modos de representação sobre a língua inglesa de futuros professores desta língua em processo de formação inicial, conforme interagiam em fóruns online sobre temas relacionados aos estudos da linguagem. Para complementar a análise, os participantes desta pesquisa responderam a uma pergunta motivadora. As bases teóricas que sustentaram a análise foram construídas a partir das propostas de

\begin{tabular}{|l|l|l|l|l|}
\hline Ilha do Desterro & Florianópolis & n 66 & p. 173- 202 & jan/jun 2014 \\
\hline
\end{tabular}


Fairclough (2001, 2003, 2009), de uma abordagem dialético-relacional de Análise de Discurso Crítica, principalmente o que se refere a discursos enquanto representação, e de van Dijk (2008, 2009), de uma abordagem sócio-cognitiva de Estudos Críticos de Discurso, principalmente ao que se refere a modos de representação. Os resultados obtidos de certa forma convalidaram um discurso latente de hegemonia da língua inglesa. Foram encontradas, no entanto, discrepâncias nos modos de representar a língua inglesa entre o discurso natural e o discurso motivado pela pergunta.

Palavras-chave: Língua Inglesa; Análise de Discurso Crítica; Modos de Representação.

\section{Abstract}

This is an exploratory research with ethnographic basis (FRAGOSO et.al. 2011), and which had as specific objectives to identify, describe and explain the modes of representation of the English language by future English teachers while they interacted in online discussion forums about themes related to language studies in general, in a pre-service teacher education program. To complement the analysis, the research participants answered a motivating question. The theoretical bases on which this research was built were the dialectical-relational approach to Critical Discourse Analysis of Fairclough (2001, 2003, 2009), especially what refers to discourses as representations, and the sociocognitive approach to Critical Discourse Studies of van Dijk (2008, 2009), especially what refers to modes of representation. The results could somehow validate a common discourse of the English language hegemony. However, discrepancies were found between the modes of representation of the English language in the natural discourse and in the question-motivated discourse. Keywords: English; Critical Discourse Analysis; Modes of Representation 


\section{Introdução}

Este artigo tem como objetivo estudar os modos de representação da língua inglesa em fóruns online de futuros professores desta língua. Como objetivos específicos, buscamos identificar, descrever e explicar os modos de representação da língua inglesa na prática social dos futuros professores, em processo de formação inicial, conforme interagem no ambiente pesquisado, a partir de duas perspectivas teóricas da Análise de Discurso Crítica (doravante ADC): a Abordagem Dialético-Relacional proposta por Fairclough ([1992] $2001,2003,2009)$ e a Abordagem Sociocognitiva proposta por van Dijk (2008, 2009).

A justificativa desta proposta está no fato de que a língua inglesa é referida amplamente nos dias atuais como uma língua franca para a comunicação internacional, muitas vezes nomeada como inglês global', sem evocar uma reflexão crítica sobre a espessura cultural que ela pode carregar, principalmente, o que se relaciona a questões de hegemonia e ao imperialismo linguístico (PHILLIPSON, 1992).

Enquanto língua franca, o inglês é tratado como a língua da 'globalização', que serve à necessidade de uma língua comum para a comunicação entre povos de países falantes de línguas diferentes, "ao menos em meio às categorias mais 'globalizadas' de sua população" (LACOSTE, 2005, p.8). Sob essa luz, podemos inferir que a língua inglesa pode receber um valor de prestígio ao promover ascensão e acesso a esferas sociais mais globalizadas, ajudando a demarcar uma geopolítica que se constrói por meio dos usos da língua e que, por sua vez, implica rivalidade de poderes e de influências entre os povos oficialmente e os não oficialmente anglófonos. Pesquisas têm apontado (RAJAGOPALAN, 2005) que os países não anglófonos, em especial os países considerados periféricos à globa- 
lização, são vítimas das políticas discriminatórias impostas pelos países anglófonos, revelando a supremacia, o controle e a hegemonia da língua inglesa.

Por pertencer à esfera de práticas sociais é preciso abordar os usos da língua inglesa com um olhar que não seja puramente linguístico. As duas perspectivas da ADC que convocamos para este estudo podem ajudar a alcançar os objetivos propostos. A Abordagem Sociocognitiva de van Dijk (op.cit.) contempla o estudo das práticas sociais a partir do triângulo: discurso - cognição - sociedade, ajudando a identificar como o conhecimento é construído e partilhado nas interações dos fóruns; e a Abordagem Dialético-Relacional proposta por Fairclough (op.cit.) ajuda a estudar as práticas sociais em sua relação dialética com as estruturas e os eventos sociais, principalmente no que se refere a discursos e representações.

Orientado pelo estudo do texto, Fairclough (op.cit.) propõe estudá-lo como a instância real de uso da língua por meio de uma análise com base na Linguística Sistêmico-Funcional (doravante LSF) hallidiana que, por sua vez, preocupa-se com a relação entre a língua e os outros elementos e aspectos da vida social, considerando sua forma, seus significados e seus efeitos. A Perspectiva Sociocognitiva de van Dijk (2009), por sua vez, considera fundamental a importância dos estudos da cognição em termos de representações mentais e de processos envolvidos nos usos da língua na produção e compreensão de discursos durante interações verbais.

Nossa proposta não é de forma alguma inovadora. O tema vem sendo amplamente pesquisado em diferentes países e encontra-se também como uma das preocupações centrais dos estudos que, de uma perspectiva ecológica (CREESE et.al. 2008), buscam descortinar relações entre usuários da língua inglesa em ambientes variados no atual contexto globalizado caracterizados pela diversidade étnica 
e religiosa, relações de poder econômicas e/ou políticas desiguais e abusivas, relações entre línguas majoritárias e minoritárias, violência material e/ou simbólica contra minorias e (in)justiça social, políticas de inclusão e letramentos etc. No Brasil, vale mencionar os trabalhos de Moita Lopes (2008) e Rajagopalan (2005).

No campo de ensino e aprendizagem da língua inglesa, pesquisas apontam que os fatores acima mencionados impactam as motivações dos aprendizes de variadas maneiras (RIBEIRO-SILVA, 2012). Nessa perspectiva ecológica, interessam-nos os modos de representar a língua inglesa que os futuros professores em formação inicial constroem no contexto em que pesquisamos, por ser um ambiente diferenciado de interação online, e por acreditarmos que esses modos de representação interagem com discursos enquanto prática social instanciados em outros eventos sociais fora da sala de aula. Ainda, justificamos este estudo pela nossa preocupação acerca das influências que esses modos de representar podem ter na própria aprendizagem da língua inglesa e na futura prática docente dos participantes dessa pesquisa.

Discutimos, a seguir, a ADC conforme a abordagem de Fairclough, principalmente no que se refere a discursos enquanto representação e os ECDs, conforme a abordagem de van Dijk sobre os modos de representação. Logo depois apresentamos a metodologia, descrevendo a natureza desta pesquisa e os procedimentos de reunião e análise de dados. Após, trazemos a análise e a discussão dos dados para, finalmente, discutirmos o alcance dos objetivos e concluirmos com futuros encaminhamentos.

Esperamos, ainda, que este artigo contribua com o leitor ao apresentar uma intersecção nas teorias convocadas e lançar luz sobre uma maneira de se investigar modos de representação. 


\section{Modos de representação na Análise de Discurso Crítica e nos Estudos Críticos do Discurso}

A proposta geral da Análise de Discurso Crítica (ADC) é contribuir com a pesquisa de problemas sociais diários, como a injustiça, a desigualdade, a falta de liberdade etc., por meio da análise de suas fontes e causas e as possibilidades de superá-los. A contribuição de Fairclough ([1992] 2001, 2003, 2009) para este campo de investigação se dá por meio de uma abordagem das relações dialéticas entre as várias modalidades semióticas, das quais a língua é considerada apenas mais um componente entre outros elementos sociais.

A abordagem do discurso e da análise de discurso proposta por Fairclough, em seu livro "Discurso e mudança social" ([1992] 2001), busca integrar diferentes perspectivas e métodos com a finalidade de propor um quadro teórico para o estudo das dimensões discursivas da mudança social e cultural. Com a intenção de combater a visão comum de discurso enquanto apenas uso da linguagem falada ou escrita, Fairclough propõe um quadro teórico tridimensional ancorado em uma perspectiva dialético-relacional, que define discurso enquanto texto, enquanto prática discursiva e enquanto prática social, ressaltando que o discurso é também um modo de ação e de representação em nível social. Isso implica que existe uma relação dialética entre discurso e estrutura social em que o discurso é tanto uma condição quanto um efeito dela, e contribui para a construção de identidades, a construção das relações entre as pessoas e a construção de sistemas de conhecimento e crenças.

Nestas relações dialéticas, o autor destaca três categorias: os gêneros, os discursos e os estilos. Os gêneros são entendidos como os modos semióticos de agir e interagir; os discursos são os modos semióticos de construir aspectos do mundo, sejam físicos, sociais ou 
mentais, que podem ser identificados como diferentes posições ou perspectivas de diferentes grupos ou atores sociais; e os estilos são as identidades ou modos de ser no seu aspecto semiótico (2009, p. 164). A partir dessa tríade, o autor relaciona três modos principais nos quais a semiótica se relaciona a outros elementos das práticas sociais e dos eventos sociais: como uma faceta da ação (gêneros), como representação dos aspectos do mundo e experiências nele vividas (discursos) e como constituição de identidades (estilos).

Van Dijk prefere o termo Estudos Críticos do Discurso (ECD) em vez de Análise de Discurso Crítica (ADC) justificando que, diferentemente do que propõe Fairclough, prefere não associar uma teoria crítica a um modelo de análise. Van Dijk (2009) considera o termo ECD mais amplo e que favorece pensar em um campo multidisciplinar de atividade que não se limita a análise. A preocupação desse autor é tratar de problemas sociais como formas de abuso de poder que resultam na desigualdade social; analisar e avaliar, de uma perspectiva normativa dos direitos humanos, as práticas discursivas abusivas, levando em consideração a resistência de grupos vitimizados pela injustiça social e suas consequências.

Em sua proposta sócio-cognitiva de estudos do discurso, van Dijk (2009, p. 65) estabelece a tríade "discurso - cognição - sociedade" como base linguística fundamental para estudar a interface sócio-cognitiva do discurso por meio das relações entre a mente, a interação discursiva e a sociedade. Considera, por isso, que a base linguística é fundamental para a realização desses estudos, que devem contar com a análise detalhada de estruturas, estratégias e funções do texto e da conversa. Por isso, inclui formas gramaticais, pragmáticas, interacionais, estilísticas, retóricas e semióticas no estudo dos significados das escolhas linguísticas, paralinguísticas e multimodais dos eventos comunicativos. 
O conceito de cognição nos ECD é definido como "representações e processos mentais dos usuários de uma língua quando produzem e compreendem discursos, participam da interação verbal, assim como o conhecimento, ideologias e outras crenças de grupos sociais" (2009, p. 64). Ainda, entende-se aqui que as crenças e os processos mentais dos usuários de uma língua revelam diferentes formas de representação de atitudes, valores, normas e ideologias, as quais, por sua vez, influenciam a construção de modelos mentais individuais que, quando partilhados socialmente, podem ser entendidos como modelos mentais sociais. É por essa razão que o autor propõe o estudo dos aspectos micro e macrotextuais no que se refere a:

- membros individuais e grupos sociais

- ações locais e processos

- modelos de contextos pessoais e estrutura social

- cognição pessoal e cognição social (VAN DIJK , 2008, p. 116117)

Dessa maneira, entende-se que as representações sociais influenciam a construção de modelos pessoais individuais, ou seja, o conhecimento partilhado socialmente é instanciado em modelos mentais, considerados a interface entre o social e o individual, e que sua análise permite explicar como as crenças de um grupo podem afetar as crenças pessoais expressas no discurso.

É nesse sentido que o autor define o conceito de ideologia, como crenças sociais que organizam e controlam as representações sociais, reproduzidas e expressas no discurso e que podem influenciar os modelos mentais de contextos preferidos. À luz dessa perspectiva, controlar o discurso é uma forma de poder e de controle das mentes e das ações das pessoas que, enquanto receptores de 
discursos, tendem a aceitar crenças, conhecimentos e opiniões que são transmitidos através do discurso produzido por aqueles que são considerados fontes autorizadas, confiáveis ou críveis, como acadêmicos, peritos etc., sem um pensamento consciente ativado, e portanto, crítico.

Um aspecto fundamental do quadro triádico proposto por ambos os autores, respeitando as dimensões e a natureza diferenciada de cada um, é a tentativa de fazer conexões explanatórias entre a natureza dos processos discursivos em instâncias particulares e a natureza das práticas sociais de que fazem parte. Fairclough aponta uma limitação nos estudos dos processos sócio-cognitivos, em geral, sobre a maneira como o contexto afeta a interpretação de um texto. $\mathrm{O}$ autor salienta que entender o contexto ajuda a diminuir a ambivalência na interpretação dos textos, pois nele podemos encontrar orientações sobre como o texto deve ser interpretado, por meio da sinalização de pistas socialmente construídas que dependem do contexto, aferir a inter-relação entre os participantes da interação e os recursos disponíveis a eles para a produção, distribuição e interpretação dos textos.

Fairclough também propõe uma discussão sobre os conceitos de ideologia e hegemonia para o estudo de discurso enquanto prática social. Isso porque, para o autor, as práticas discursivas são investidas ideologicamente à medida que incorporam significações que contribuem para manter ou reestruturar as relações de poder na estrutura social, assim como de dominação, com base na classe social, gênero, grupo cultural etc. Assim como van Dijk, Fairclough pressupõe que as pessoas não têm consciência das dimensões ideológicas de sua própria prática. No entanto, para este autor, os sujeitos são posicionados ideologicamente e capazes de agir criativamente no sentido de realizar suas próprias conexões entre as diversas práticas e as estruturas posicionadoras (FAIRCLOUGH, 2001, p. 121). 
A ideologia está localizada tanto nas estruturas (ordens de discurso) quanto no resultado de eventos passados, nas condições para os eventos atuais e nos próprios eventos quando as reproduzem e, por conseguinte, transformam as estruturas condicionadoras. Podemos estudar a ideologia por meio da semântica do estudo das metáforas, das pressuposições, da coerência, da transitividade, da tomada dos turnos de fala, no caso da oralidade, convenções de polidez, enfim, como uma propriedade de estruturas e uma propriedade de eventos ao mesmo tempo, numa relação dialética.

O conceito de hegemonia é definido por Fairclough (2001) como a dominação nos domínios econômicos, políticos, culturais e ideológicos da sociedade, que se dá pela aliança de classes economicamente definidas com outras forças sociais causando um "equilíbrio". No quadro tridimensional de análise de discurso, o conceito de hegemonia fornece uma matriz para analisar a prática social à qual pertence o discurso em termos de relações de poder que reproduzem, reestruturam e desafiam o "equilíbrio" das ordens do discurso.

Interessa-nos, neste estudo, a maneira como os discursos contemplam modos de representar aspectos do mundo, seus processos, relações e estruturas do mundo material, do mundo mental dos pensamentos, sentimentos, crenças e assim por diante, e do mundo social. Entendendo discursos enquanto representações, aspectos particulares do mundo podem ser apresentados de maneira diferente, por meio de diferentes discursos que, por sua vez, podem ser entendidos como diferentes perspectivas sobre o mundo. Fairclough propõe que discursos enquanto representação sejam estudados da seguinte forma: (i) representação de eventos sociais, (ii) representação como recontextualização, e (iii) representação de processos, participantes e circunstâncias (práticas sociais, atores sociais, tempo e espaço). Selecionamos esta última forma de estudar discursos enquanto repre- 
sentação conforme os objetivos que propusemos para esta pesquisa.

Chouliaraki; Fairclough (1999) encaminham as categorias da Linguística Sistêmico Funcional (LSF) como uma maneira apropriada de se analisar o discurso orientado pelo texto. Para a análise dos modos de representar que propomos neste trabalho, concentramos nosso olhar para as formas de atividade e as pessoas, suas relações sociais com os objetos e os meios, o tempo, os espaços e a linguagem. Apoiamo-nos, então, conforme já expusemos anteriormente, na análise da representação dos processos, dos participantes e das circunstâncias em que são instanciados no texto. Fairclough destaca que os processos são normalmente representados por meio do uso de verbos, os participantes por meio de sujeitos e objetos desses verbos e as circunstâncias por meio de diferentes complementos adverbiais.

De acordo com Halliday; Mathiessen (2004), os processos em que a experiência de mundo é instanciada no texto podem ser divididos num sistema de transitividade que se divide em três grupos: o material, o mental e o relacional. Outros grupos que podem representar experiências e que tomamos como categorias de análise são os processos verbais, os comportamentais e os existenciais.

Buscamos identificar nas orações estudadas os participantes que agem nos processos enquanto sujeitos e objetos dos verbos em que são instanciados e as circunstâncias da sua realização. Após a identificação, utilizamos a categoria de polarização proposta por van Dijk (2008), entre "nós"/ "eles" para verificar o modelo preferencial de representação dos participantes nos processos analisados. Van Dijk considera que a polarização é uma estratégia de uso da língua de auto-representação positiva ou negativa bastante típica em discurso tendencioso dos fatos em favor dos interesses próprios do falante e dos escritores. Essa estratégia pode ser aplicada em vários níveis do discurso: 
- estratégias gerais de interação (auto-apresentação positiva, outro-apresentação negativa);

- macroato de fala indicando nossos "bons" atos e os "maus" atos dos outros; por exemplo, acusação/defesa;

- macroestruturas semânticas: seleção de tópicos (desenfatizar pontos negativos ou positivos sobre nós/eles);

- atos de fala locais de discurso estabelecendo e sustentando atos de fala globais, por exemplo, declarações que comprovem acusações;

- significados locais de ações positivas/negativas nossas/deles (fornecer muitos/poucos detalhes; generalizar/ser específico; ser vago/preciso; ser explícito/implícito etc);

- léxico: selecionar palavras positivas para nós, palavras negativas para eles;

- sintaxe local: orações ativas versus passivas, nominalizações: (des)enfatizar a agência, a responsabilidade positiva/negativa nossa/deles;

- figuras retóricas: hipérboles versus eufemismos para significados positivos/negativos; metonímias e metáforas enfatizando propriedades negativas/positivas nossas/deles;

- expressões sonoras e visuais: enfatizar (volume alto etc.; fonte grande, em negrito etc.) significados positivos/negativos; ordem (primeiro, segundo; na parte superior/inferior da página etc.); significados positivos/negativos (VAN DIJK, 2008, p. 252-253).

Van Dijk (op.cit.) acredita que essas estratégias e movimentos em vários níveis de discurso podem estabelecer um quadro ideológico usual da polarização de um grupo discursivo que, por sua vez, podem envolver sentimentos nacionalistas em termos de valores e que a falta de conhecimento explícito na recepção dos textos contribui para a legitimação da desigualdade social condicionando a construção de modelos de contexto dos participantes e, consequentemente, controlando suas interações e discursos. 
Tendo apresentado nosso percurso teórico que embasa a proposta desse estudo, trazemos, a seguir, a metodologia da pesquisa.

\section{Metodologia}

Trata-se de uma pesquisa pautada em princípios etnográficos nos termos de Fragoso et. al. (2011, p. 180-181.), que recomendam a etnografia como apropriada para a pesquisa na Internet (consideram tanto o ambiente online quanto o offline) por permitir estudar questões ou comportamentos sociais que ainda não são claramente compreendidos, conhecer a perspectiva dos participantes da pesquisa sobre os contextos em que estão inseridos, registrar um processo, ir a campo, selecionar, observar, documentar (salvando em arquivos e mensagens, fazendo printscreens ${ }^{1}$, efetuando downloads de materiais etc.), questionar e analisar, ressaltando a importância de três fronteiras (espacial, temporal e relacional) e três esferas de influência (analítica, ética e pessoal) para a construção do campo pesquisado.

O contexto da pesquisa foi o Curso de Letras/Inglês ofertado na modalidade semi-presencial na região nordeste do Brasil, hospedado num AVA reconhecido como Solar. Para a reunião dos dados, foi selecionada uma turma de 38 (trinta e oito) alunos e seu professor/ tutor $^{2}$ na disciplina Teorias de Língua e de Segunda Língua, cujos temas propostos para discussão em fórum contemplavam os conteúdos programados para o alcance dos objetivos da disciplina, a saber: conceitos de língua e de segunda língua, linguagem e Linguística; princípios gerais do estruturalismo, gerativismo e funcionalismo; e linguagem e sociedade. Percebe-se que não era proposto ao aluno discutir especificamente a língua inglesa, isso porque nos interessava saber como os modos de representar esta língua naturalmente atravessavam o discurso dos futuros professores. 
A pesquisadora atuava nesse contexto como a professora coordenadora da disciplina, e estava presente no ambiente virtual pesquisado, podendo interferir por sua iniciativa ou quando solicitada, na interação que ali se construía. No entanto, não houve registros de sua participação direta nos fóruns pesquisados.

De um número total de 489 (quatrocentos e oitenta e nove) mensagens enviadas no fórum, foram encontradas 10 (dez) mensagens que continham menção à língua inglesa. Essas mensagens foram tratadas como dados primários, e submetidos à análise. A partir das asserções levantadas nessa análise, buscamos convalidá-las nos dados gerados por meio de uma outra ferramenta de pesquisa, a qual nomeamos depoimentos escritos. Para a geração desses dados, foi pedido que os alunos respondessem de maneira escrita a uma pergunta, a saber, "Qual o papel da língua inglesa no mundo em que vivemos?" As respostas dos alunos foram submetidas ao mesmo tratamento analítico realizado nos dados primários com a intenção de podermos triangular a recorrência dos modos de representação.

O tratamento de análise foi pautado na LSF, com foco na transitividade, da perspectiva da representação de processos (análise de verbos ou processos nominalizados), dos participantes (sujeitos e objetos) e circunstâncias (advérbios), que se organizam em configurações e oferecem modelos ou esquemas para construir a experiência sobre o que acontece no mundo material e no mundo mental: o processo se desenrola no tempo, os participantes envolvidos no processo e as circunstâncias associadas ao processo. Acreditamos que por meio dos discursos, dessa maneira, modelos do contexto preferido são projetados nas práticas sociais durante a interação verbal, aproximando-se aqui com a proposta de van Dijk (2008). Assim, utilizamos a categoria de polarização de van Dijk (op. Cit.) no estudo da representação dos participantes acerca de processos 
sociais instanciados nos proferimentos ("nós"/ "eles") para podermos analisar os modos preferidos de representação dos participantes instanciados no texto.

Tomamos como modelo de análise o seguinte quadro proposto por Ticks (2007, p. 179), aqui adaptado com dados extraídos do corpus de nossa pesquisa:

\begin{tabular}{|c|c|c|}
\hline $\begin{array}{l}\text { Tipos de } \\
\text { processos }\end{array}$ & Significado da categoria & Exemplos de processos \\
\hline Materiais & $\begin{array}{l}\text { Estão relacionados com } \\
\text { o mundo da experiência. } \\
\text { Constroem a ideia de } \\
\text { mudança concreta num } \\
\text { fluxo de eventos pelo uso } \\
\text { da energia (HALLIDAY; } \\
\text { MATTHIESSEN, 2004, p. } \\
\text { 179). }\end{array}$ & $\begin{array}{l}\text { Fazer, realizar, construir. } \\
\text { Ex 1:... uma volta às origens do } \\
\text { "português puro" ou um dialeto } \\
\text { tipo "internetês" com grande in- } \\
\text { fluência do inglês? } \\
\text { Ex 2: A língua inglesa reprim- } \\
\text { indo a possível difusão de outras } \\
\text { línguas. }\end{array}$ \\
\hline Mentais & $\begin{array}{l}\text { Estão relacionados com o } \\
\text { mundo da nossa consciên- } \\
\text { cia. Mudam a percepção } \\
\text { que temos da realidade, } \\
\text { construindo o processo da } \\
\text { própria consciência (HAL- } \\
\text { LIDAY; MATTHIESSEN, } \\
\text { 2004, p. 107-8). }\end{array}$ & $\begin{array}{l}\text { Cognitivos: pensar, refletir, en- } \\
\text { tender, acreditar, querer, amar, } \\
\text { Perceptivos: ver, ouvir, cheirar. } \\
\text { Afetivos: gostar, odiar. } \\
\text { Ex 1: Países escandinavos onde } \\
\text { mais de } 90 \% \text { da população domina } \\
\text { o inglês além do sueco. }\end{array}$ \\
\hline Relacionais & $\begin{array}{l}\text { Representam as categorias } \\
\text { de atribuição e identifica- } \\
\text { ção. Pertencem aos proces- } \\
\text { sos de "ser" (HALLIDAY; } \\
\text { MATTHIESSEN, 2004, p. } \\
\text { 210-11). }\end{array}$ & $\begin{array}{l}\text { Parecer, tornar-se, ficar, ter, possuir, } \\
\text { pertencer, significar, . } \\
\text { Ex 1:... que por meio de suas } \\
\text { empresas multinacionais exige que } \\
\text { empregados dos cinco continentes } \\
\text { se tornem falantes da língua da } \\
\text { matriz } \\
\text { Ex 2: Assim, a língua estadunidense } \\
\text { torna-se dominante no mundo dos } \\
\text { negócios. }\end{array}$ \\
\hline
\end{tabular}




\begin{tabular}{|l|l|l|}
\hline Verbais & $\begin{array}{l}\text { Pertencem aos processos de } \\
\text { "dizer" (HALLIDAY; MAT- } \\
\text { THIESSEN, 2004, p. 252) }\end{array}$ & $\begin{array}{l}\text { Falar, dizer, conversar, culpar, criti- } \\
\text { car, pedir, explicar, questionar. } \\
\text { Ex 1: Midiaticamente, isto também } \\
\text { é visível porque bandas de rock da } \\
\text { região escandinava compõem as } \\
\text { letras de suas músicas em inglês. }\end{array}$ \\
\hline $\begin{array}{l}\text { Comporta- } \\
\text { mentais }\end{array}$ & $\begin{array}{l}\text { São os processos tipica- } \\
\text { mente humanos, fisiológi- } \\
\text { cos e psicológicos (es- } \\
\text { catológicos) (HALLIDAY; } \\
\text { MATTHIESSEN, 2004, p. } \\
\text { 248). }\end{array}$ & $\begin{array}{l}\text { Respirar, tossir, rir, chorar, cantar, } \\
\text { sonhar. } \\
\text { (não foram encontradas ocor- } \\
\text { rências de representação deste } \\
\text { processo) }\end{array}$ \\
\hline Existenciais & $\begin{array}{l}\text { Processos expressos pelos } \\
\text { verbos haver e existir } \\
\text { (HALLIDAY; MATTHIES- } \\
\text { SEN, 2004, p. 256). }\end{array}$ & $\begin{array}{l}\text { Haver, existir, ter. } \\
\text { Ex 1: ... e 90\% do conteúdo da } \\
\text { Internet são em inglês }\end{array}$ \\
\hline
\end{tabular}

Tabela 1 - Modelo de análise dos modos de representação de processos

Na próxima seção, seguimos com a análise dos dados selecionados para identificar, descrever e explicar os modos de representar a língua inglesa no discurso construído no ambiente estudado.

\section{Análise e discussão dos dados dos fóruns de discussão}

Das dez mensagens reunidas nos fóruns em que ocorriam proferimentos sobre a língua inglesa, foram analisadas 28 (vinte e oito) sentenças na perspectiva da LSF, conforme traziam a língua inglesa representada como participante dos processos, ou seja, enquanto sujeito ou enquanto objeto dos verbos em que os processos ${ }^{3}$ eram instanciados. Dessa maneira, dividimos a análise dessas vinte e oito sentenças em dois blocos: um em que a língua inglesa era instanciada como objeto do verbo, e outra enquanto sujeito.

Os modos de representar a língua identificados podem ser resumidos como: "estrangeiros (principalmente falantes do inglês como 
língua materna) usam a língua inglesa em seus países com finalidade econômica e de comunicação (mídia)" e "a língua inglesa domina e influencia outros povos e outras culturas (incluindo sua língua) principalmente em situações econômicas e de comunicação (mídia)". A seguir, apresentamos uma discussão acerca dos dados analisados sobre cada modo de representar a língua inglesa identificados nos dados.

Estrangeiros (principalmente falantes do inglês como língua materna) usam a língua inglesa em seus países com finalidade econômica e de comunicação (mídia) 4 .

Os participantes ativos dos processos que tomam a língua enquanto objeto, foram, predominantemente, representados pelos americanos, estrangeiros, região escandinava, a Internet, ou seja, "eles", como segue abaixo:

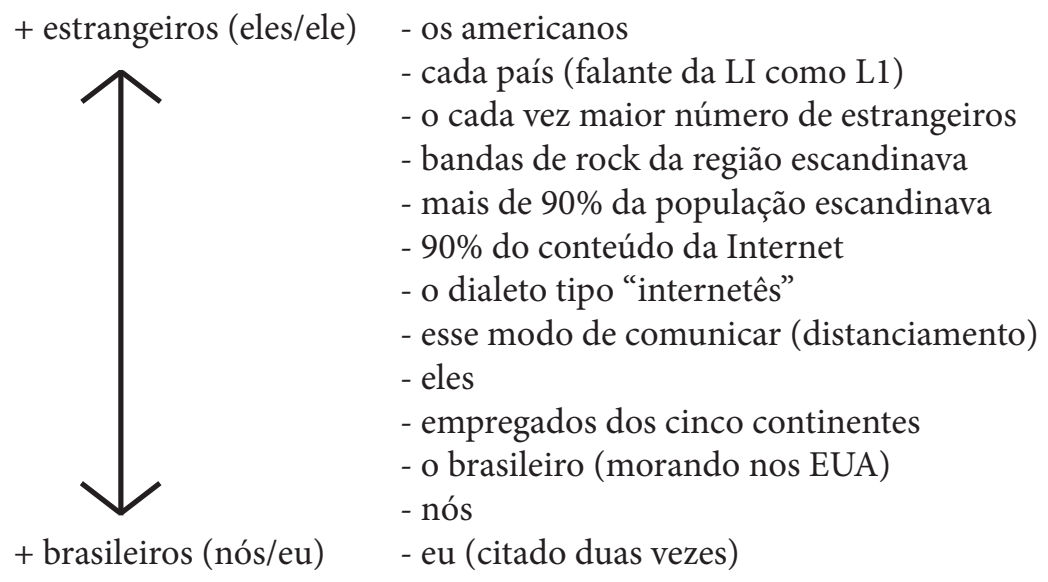

Esquema 1 - Representação dos participantes ativos dos processos em que a língua inglesa é objeto. 
A partir da categoria de polarização proposta por van Dijk (2008), percebemos que os participantes representados como atores desses processos são, em sua maioria, outros que não os próprios participantes da pesquisa. O pronome pessoal em primeira pessoa foi usado duas vezes no singular e uma no plural, sendo os outros onze processos realizados por atores como os estrangeiros, os americanos, conforme mostra o esquema acima. A partir dessa constatação, podemos dizer que os participantes desta pesquisa não se representam como atores dos processos verbais e mentais de falar ou aprender a língua, em geral. O distanciamento implicado nas representações desses processos se refere tanto ao uso da língua quanto às circunstâncias em que ela é usada, instanciadas em "tempos atuais", "no dia a dia", e em lugares representados como nos Estados Unidos, nas empresas multinacionais, em países escandinavos ou em que se fale inglês, países de culturas diferentes e na mídia, principalmente a Internet.

Não houve ocorrência de representação circunstancial que incluísse alguma situação social específica do Brasil, ou em que os participantes da pesquisa estivessem nela representados, ou seja, as circunstâncias representadas em que a língua é usada são lugares distantes, diferentes, principalmente os Estados Unidos, que teve duas ocorrências.

Os processos, por sua vez, foram predominantemente verbais e mentais, o que pode ser justificado pelo participante objeto do processo, uma língua, conforme mostra a tabela abaixo:

\begin{tabular}{|l|l|l|}
\hline Processos & Ocorrências & Verbos \\
\hline Verbais & 6 & $\begin{array}{l}\text { compor, falar, utilizar (a língua), criar/ } \\
\text { utilizar (a língua), citar, falar }\end{array}$ \\
\hline Mentais & 4 & $\begin{array}{l}\text { aprender, dominar, perceber, ficar } \\
\text { sabendo }\end{array}$ \\
\hline
\end{tabular}




\begin{tabular}{|l|l|l|}
\hline Relacionais & 2 & tornar-se, ter \\
\hline Materiais & 1 & Modificar \\
\hline Existenciais & 1 & ser (em inglês) \\
\hline
\end{tabular}

Tabela 2 - Representação dos processos em que a língua inglesa é instanciada como objeto.

A representação dos processos revela o grau de apropriação atribuído aos participantes ativos descritos anteriormente em relação a língua inglesa, pelos verbos “aprendem”, “dominam”, "percebem”, "falam", "utilizam", "criam" etc.

A língua inglesa domina e influencia outros povos e outras culturas (incluindo sua língua) principalmente em situações econômicas e de comunicação (mídia).

No bloco em que a língua inglesa foi instanciada como sujeito do verbo, enquanto participante ativo realizou processos predominantemente relacionais, instanciados principalmente pelo verbo "ser", seguidos de complementos nominais compostos de palavras com sentido atributivo como: dominante, mutante, atualizada, líder, mundial. Em segundo lugar, vemos os processos materiais, como expandir-se, espalhar-se, absorver, reprimir, influenciar:

\begin{tabular}{|l|l|l|}
\hline Processos & Ocorrências & Verbos \\
\hline Relacionais & 8 & $\begin{array}{l}\text { tornar-se (dominante); passar a ser (o la- } \\
\text { tim/língua dominante); ter (um zilhão de } \\
\text { expressões); ser (a língua dominante), ser } \\
\text { (mutante), ser (atualizada), ser (lider- } \\
\text { ança), ser (mundial) }\end{array}$ \\
\hline
\end{tabular}




\begin{tabular}{|l|l|l|}
\hline Materiais & 5 & $\begin{array}{l}\text { expandir-se/espalhar-se, absorver, rep- } \\
\text { rimir; em detrimento, influenciar (ter } \\
\text { grande influência) }\end{array}$ \\
\hline Existenciais & 1 & haver (inúmeros dialetos) \\
\hline
\end{tabular}

Tabela 3 - Representação dos processos em que a língua inglesa é instanciada como sujeito.

Podemos afirmar, pelos modos de representação dos processos em que a língua é participante ativo, instanciada como sujeito, que esta tem poder, no sentido não só de "ser dominante, atual e líder", mas também de "expandir-se", "espalhar-se", "influenciar" e até mesmo "reprimir" as demais línguas, processos que personificam um organismo vivo, o que reforça a hegemonia anglófona.

Da mesma maneira em que as circunstâncias de realização desses processos foram representadas quando a língua inglesa era instanciada como participante passivo deles, aqui temos o tempo como "atual", "nos dias de hoje", e os espaços como os Estados Unidos, o mundo dos negócios e a mídia, principalmente a Internet.

Dessa forma, a partir dessas constatações, que os participantes desta pesquisa representam a língua inglesa como agente de processos de dominação, imposição, repressão e assim por diante que agem sobre outros participantes como outras línguas, outros povos e outras culturas, em circunstâncias da atualidade e circunscritas aos Estados Unidos, à mídia e ao mercado econômico. Também afirmamos que os participantes de nossa pesquisa não se representam como participantes ativos desses processos, mais uma vez, já que, desta vez, em momento algum fizeram referência a elementos de uma situação social em que estivessem também nela representados de alguma maneira. 
Levantamos, a partir dessas constatações, as seguintes asserções sobre os modos de representar a língua inglesa a partir da análise do discurso dos participantes desta pesquisa nos fóruns pesquisados:

1. Estrangeiros (principalmente falantes do inglês como língua materna) usam a língua inglesa em seus países com finalidade econômica e de comunicação (mídia).

2. A língua inglesa domina e influencia outros povos e outras culturas (incluindo sua língua) principalmente em situações econômicas e de comunicação (mídia).

\section{Análise e discussão dos dados dos depoimentos escritos}

Conforme o desenho metodológico para a análise dos dados, prosseguimos então com a identificação e a descrição dos modos de representar a língua inglesa nos dados secundários, que foram os gerados por meio de depoimentos escritos dos futuros professores a partir da pergunta: "Qual o papel da língua inglesa no mundo em que vivemos?"

Os modos de representar a língua inglesa identificados nesses dados podem ser resumidos como: "as pessoas usam a língua inglesa no mercado econômico e nos meios de comunicação" e "a língua inglesa é importante e necessária no mercado econômico e nos meios de comunicação". Da mesma maneira que discutimos os dados da interação natural acima, trazemos abaixo a discussão sobre os dados gerados pela pergunta motivadora seguindo os modos de representação identificados. 


\section{As pessoas (falantes do inglês) usam a língua inglesa no mercado econômico e nos meios de comunicação}

Assim como no discurso construído nos fóruns, podemos identificar que os participantes ativos dos processos nos 18 (dezoito) depoimentos escritos enviados à pesquisadora, dos quais extraímos 54 (cinquenta e quatro) sentenças para submetermos à análise, verificamos que os modos de representar também sinalizavam distanciamento entre nós (participantes da pesquisa) e eles (falantes de inglês):

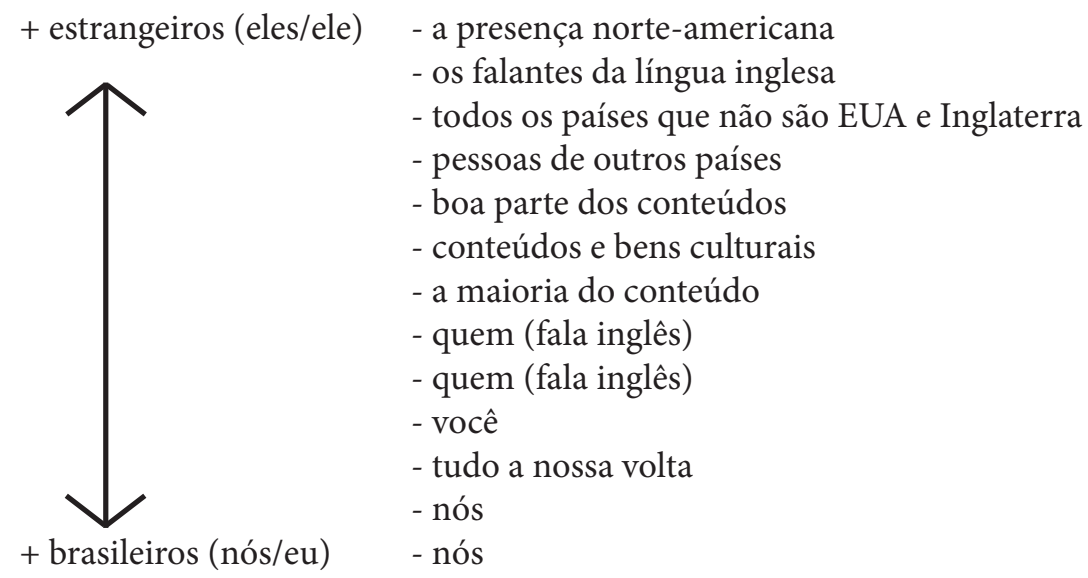

Esquema 2 - Representação dos participantes ativos dos processos em que a língua inglesa é objeto.

Em comparação com a representação analisada no esquema 1 anterior, aqui vemos que a polarização é menor: a ocorrência de participantes ativos representados como nativos concorre com conteúdos disponibilizados na mídia, e usuários da língua de uma maneira geral.

Os dezesseis (16) processos realizados pelos participantes ativos representados (predominantemente "eles") usuários da língua inglesa, que aqui eram então participantes passivos, foram os seguintes: 


\begin{tabular}{|l|l|l|}
\hline Processos & Ocorrências & Verbos \\
\hline Relacionais & 5 & $\begin{array}{l}\text { ser (em inglês); estar/ estar relacionado } \\
\text { (ao inglês); colocar (no sentido de tornar- } \\
\text { se); crescer (no sentido de tornar-se } \\
\text { maior) }\end{array}$ \\
\hline Mentais & 4 & aprender, saber, estudar (inglês) \\
\hline Materiais & 3 & produzir, fazer (em inglês) \\
\hline Verbais & 4 & iniciar (um diálogo), falar \\
\hline
\end{tabular}

Tabela 4 - Representação dos processos em que a língua inglesa é instanciada como objeto.

A predominância da representação de processos relacionais, se compararmos com os processos representados na tabela 1 anterior, revela um grau menor de domínio e um grau maior de transição, ou desenvolvimento na apropriação da língua atribuído aos participantes ativos: agora eles "crescem", "tornam-se", "colocam-se"; os processos mentais também indicam um desenvolvimento na apropriação da língua: "aprendem", "estudam" etc.

Esses processos, por sua vez, foram circunstanciados predominantemente nos "tempos atuais", na mídia, principalmente na Internet, no mundo globalizado e no setor econômico. Apesar da tênue mudança nas representações, ainda podemos dizer que os modos de representar os processos de produzir, aprender, falar etc. a língua inglesa nas circunstâncias mencionadas são, novamente, centrados numa geopolítica anglófona e predominantemente representados por participantes em terceira pessoa, "eles".

\section{A língua inglesa é importante e necessária no mundo atual globalizado.}

$\mathrm{Na}$ análise das trinta e oito (38) sentenças em que a língua inglesa foi instanciada como participante ativo do processo, ou seja, su- 
jeito do verbo, identificamos que os processos predominantes foram os seguintes:

\begin{tabular}{|l|l|l|}
\hline Processos & Ocorrências & Verbos \\
\hline Relacionais & 32 & $\begin{array}{l}\text { tornar-se (comum), tornar-se (comum), } \\
\text { parecer (moderna e descolada), tornar- } \\
\text { se (efetiva), ter (função de unir), ter } \\
\text { (função de comunicação), } \\
\text { ser (essencial), ser (necessário), ser (um } \\
\text { passaporte), ser (importante), ser (fun- }\end{array}$ \\
\hline & $\begin{array}{l}\text { damental), ser (universal), ser (global), } \\
\text { ser (importantíssima), ser (universal e } \\
\text { global), ser (onipresente), ser (vital), ser } \\
\text { (necessária), ser (importante), ser (um } \\
\text { elo), ser (universal), ser (universal), ser } \\
\text { (comum), ser (união), ser (universal), } \\
\text { ser (muito falada), ser (oficial) }\end{array}$ \\
\hline Materiais & 6 & $\begin{array}{l}\text { nascer, dominar, invadir, abrir, propor- } \\
\text { cionar, abrir }\end{array}$ \\
\hline
\end{tabular}

Tabela 5 - Representação dos processos em que a língua inglesa é instanciada como sujeito.

Visivelmente, o modo de representar processos foi relacional, seguido de complementos de sentido atributivo como importante, universal, comum e necessária, em geral, cujas circunstâncias são as mesmas em relação ao tempo, (atualidade), e espaço (setor econômico, mundo global), apesar de que essas circunstâncias foram predominantemente representadas como um contexto em que o participante da pesquisa se projetava em primeira pessoa, como "o mundo em que vivemos", o que pode ser justificado pela pergunta motivadora do depoimento escrito. 
Por fim, podemos dizer que as asserções levantadas a partir da análise dos dados primários não foram totalmente convalidadas com o cruzamento dos dados secundários, já que nestes últimos dados os participantes ativos dos processos em que a língua inglesa era tomada como objeto não eram representados predominantemente como estrangeiros, mas sim conteúdos e falantes da língua de um modo geral.

Ainda que não haja uma projeção explícita do participante da pesquisa enquanto participante do processo, de maneira geral, ainda permanece como um discurso polarizado. Outra asserção poderia ser levantada a partir dos dados secundários: "Pessoas usam a língua inglesa no mercado econômico e nos meios de comunicação". Uma outra leve diferença em comparação com os dados primários, aqui não encontramos uma forte representação da língua inglesa enquanto agente de processos de dominação e influência sobre outros povos e culturas, mas sim como "uma língua importante e necessária por ser universal nas mesmas circunstâncias acima mencionadas".

A seguir discutimos os resultados, conclusões e encaminhamentos desta pesquisa.

\section{Resultados, conclusões e encaminhamentos}

Os resultados da análise podem ser resumidos da seguinte maneira: no discurso natural, não monitorado pelo pensamento consciente, já que não era esperado que os participantes desta pesquisa, futuros professores da língua inglesa, falassem sobre ela, os modos de representar a língua podem ser resumidos como:

1. Estrangeiros (principalmente falantes do inglês como língua materna) usam a língua inglesa em seus países com finalidade econômica e de comunicação (mídia). 
2. A língua inglesa domina e influencia outros povos e outras culturas (incluindo sua língua) principalmente em situações econômicas e de comunicação (mídia).

Já no discurso gerado por uma pergunta motivadora, em que o pensamento consciente pudesse ser acionado, os modos de representar a língua foram os seguintes:

1. As pessoas usam a língua inglesa no mercado econômico e nos meios de comunicação.

2. A língua inglesa é importante e necessária no mercado econômico e nos meios de comunicação.

A partir dessas constatações, podemos afirmar que os modos de representar podem ser proferidos nos discursos de maneira diferente se o pensamento consciente estiver ativado, como o que aconteceu no depoimento motivado pela pergunta. A pergunta motivadora, por si, já trazia um proposição pressuposta de que "a língua inglesa tem algum papel no mundo em que vivemos" e a circunstância instanciada na pergunta "convocou" o respondente a se representar nela, de alguma forma, pelo uso da primeira pessoa em "no mundo em que vivemos".

Por outro lado, acreditamos que as condições de interação proporcionadas pelo fórum online como um ambiente virtual de aprendizagem ensejaram a participação mais igualitária e espontânea, mais característica da conversa natural. Esse resultado aponta para o fato de que dados coletados em discursos naturais podem revelar modos de representação diferentes daqueles gerados por entrevistas ou perguntas que ativem o pensamento consciente. 
Porém, em ambos os contextos de geração de dados, podemos encontrar recorrência na representação da língua enquanto instrumento de comunicação global para setores econômicos e midiáticos, o que não parece ser nada novo, já que é um discurso encontrado em outras práticas sociais fora deste contexto, também evidenciadas nas pesquisas sobre o assunto (MOITA-LOPES, 2008; RAJAGOPALAN, 2005; PHILLIPSON, 1992).

Isso pode ser explicado, ainda com base nas evidências trazidas nas pesquisas mencionadas, pela auto-representação positiva bastante típica no discurso em favor dos próprios falantes e escritores nativos da língua inglesa, que favorecem um quadro ideológico polarizado de supremacia e hegemonia da língua inglesa e que, conforme discutido na seção teórica deste artigo, contribui para a legitimação da desigualdade social evidenciada na construção de modelos de contextos em que os participantes desta pesquisa não se projetavam como agentes capazes de usar a língua, aprendê-la, ou apropriarem-se dela. Ao contrário, representam a língua inglesa como um instrumento de comunicação importante nos dias atuais, mas, predominantemente, em processos realizados por estrangeiros.

No que se refere a usos da língua no mundo globalizado, podemos inferir que a língua inglesa foi considerada como a mais importante e reproduziu uma demarcação geopolítica mais restrita a categorias "globalizadas" da população, que têm acesso aos recursos midiáticos, principalmente a Internet, e que atuam em setores econômicos demarcados por empresas multinacionais. Em outras palavras, os participantes desta pesquisa, nas práticas discursivas estudadas, não se apropriaram desta língua, de uma maneira geral.

Ressaltamos que esta pesquisa foi feita com futuros professores de língua inglesa em processo inicial de formação, ou seja, no primeiro semestre do curso. Por isso, consideramos pertinente que uma 
nova investigação seja feita com estes mesmos participantes para que se possa estudar possíveis modificações nos modos de representar a língua inglesa ao final de sua formação, já que, até lá, terão estudado várias disciplinas na língua inglesa.

Consideramos, no entanto, apesar das limitações desta pesquisa, que os resultados foram satisfatórios no sentido de poder apontar, dada a ciência dos modos de representação da língua inglesa pelos participantes desta pesquisa, caminhos para um tratamento direcionado ao longo da formação desses professores com objetivos de combater um quadro ideológico de dominação e neocolonização linguística. A importância disso se dá pelo fato de que os participantes de nossa pesquisa serão futuros professores dessa língua, ocupando um lugar de grande responsabilidade na estrutura social, podendo ajudar a legitimar essa dominação, ou a combatê-la.

\section{Notas}

1. A realização de printscreens tem sido vista como procedimentos metodológicos nos estudos em linguagem e tecnologia (YUAN, 2003; ARAÚJO, 2006).

2. Respeitamos os protocolos de ética estipulados pelo COMEPE (Comitê de Ética na Pesquisa da Universidade Federal do Ceará), conforme já vínhamos praticando em estudos anteriores neste mesmo contexto, com a devida autorização deste comitê e o consentimento e livre esclarecimento dos participantes.

3. Vale ressaltar que para os aspectos de transitividade relacionados a ativas e passivas, para cada sentença analisada, consideramos o participante agente quando sintaticamente era o sujeito ativo do verbo e, quando sintaticamente o sujeito era passivo, este foi considerado participante passivo do processo.

4. O leitor poderia questionar a asserção "estrangeiros (principalmente falantes do inglês como língua materna) usam a língua inglesa em seus países com a finalidade econômica e de comunicação (mídia)", sucitando 
outra questão: "por que falantes do inglês como língua materna falariam outra língua em seus países independentemente da finalidade?" Porém, justificamos essa asserção como o modo de representação preferido da língua inglesa instanciada como objeto do verbo mais recorrente nos dados analisados nestas circunstâncias específicas. Além disso, o leitor poderá perceber que essa asserção se torna relevante quando comparada aos modos de representação preferidos identificados nos dados gerados pela pergunta motivadora que traremos mais adiante.

\section{Referências}

ARAÚJO, J. Os chats: uma constelação de gêneros na Internet. Tese de Doutorado em Linguística. Programa de Pós-Graduação em Linguística. Universidade Federal do Ceará, Fortaleza, 2006.

CHOULIARAKI, L.; FAIRCLOUGH, N. Discourse in Late Modernity. Edinburgh University Press, 1999.

CREESE, A.; MARTIN, P.; HORNBERGER, N.H. Encyclopedia of Language and Education - Ecology of Language. Philadelphia, v. 9, 2 ed., Springer, 2008.

FAIRCLOUGH, N. A dialectical-relational approach to critical discourse analysis in social research. In: WODAK, R; MEYER, M. Methods of Critical Discourse Analysis. SAGE, p. 162-186, 2009.

FAIRCLOUGH, N. Analysing Discourse textual analysis for social research. Routledge, 2003.

FAIRCLOUGH, N. Discurso e Mudança Social. Brasilia: Editora UnB, 2001.

FRAGOSO, S. et al. Métodos de pesquisa para Internet. Porto Alegre: Sulina, 2011.

HALLIDAY, M. A. K., \& MATTHIESSEN, C. M. I. M. An Introduction to Functional Grammar (3a ed.). London: Edward Arnold, 2004.

LACOSTE, Y. Por uma abordagem geopolítica da difusão do inglês. In: LACOSTE, Y.; RAJAGOPALAN, K. (Orgs.). A geopolítica do inglês. São Paulo: Parábola Editorial, 2005, p. 7-11.

LACOSTE, Y.; RAJAGOPALAN, K. (Orgs.). A geopolítica do inglês. São Paulo: Parábola Editorial, 2005. 
MOITA-LOPES, L.P. Inglês e globalizacão em uma epistemologia de fronteira: ideologia linguística para tempos híbridos. In: D.E.L.T.A., v. 24, n.2, p. 309-340, 2008.

PHILLIPSON, R. Linguistic Imperialism. Oxford: Oxford University Press, 1992.

RAJAGOPALAN, K. A geopolítica da língua inglesa e seus reflexos no Brasil. In: LACOSTE, Y.; RAJAGOPALAN, K. (Orgs.) A geopolitica do inglês. São Paulo: Parábola Editorial, 2005, p. 135-156.

RIBEIRO-SILVA, E. Ideologia e ensino de inglês no Brasil: A aula de leitura na Escola Pública em questão. In: SILVA, K. A. DA; et. al. (Orgs.). A Formação de Professores de Linguas: Novos Olhares - Volume II. Campinas: Pontes Editores, 2012, p. 163-182.

TICKS, L. K. Representações de conceitos de linguagem, ensino e aprendizagem e de papéis no discurso de professores de inglês recém-formados. In: Linguagem e (Dis) curso - LemD, Tubarão, v. 7, 2007, p. 173-193.

VAN DIJK, T.A. Discurso e poder. São Paulo: Contexto, 2008.

VAN DIJK T.A. Critical Discourse Studies: a sociocognitive approach. In: WODAK, R.; MEYER, M. (Orgs.) Methods of Critical Discourse Analysis. SAGE, 2009, p. 62-86.

YUAN, Y. The use of Chat rooms in na EsL setting. Computers and composition: an international journal. v. 20. n. 2, p. 194-206, 2003.

(Recebido em 01/05/14. Aceito em 29/05/14) 